\title{
Communication \\ Feeding and Pore Formation in Semisolid Metal Casting
}

\author{
Anders E. W. Jarfors ${ }^{1} * \mathbb{\oplus}$, Qing Zhang ${ }^{1}$ and Stefan Jonsson ${ }^{2}$ \\ 1 Materials and Manufacturing, School of Engineering, Jönköping University, 55111 Jönköping, Sweden; \\ qing.zhang@ju.se \\ 2 Materials Science and Engineering, School of Industrial Engineering and Management, \\ Royal Institute of Technology, 10044 Stockhom, Sweden; jonsson@kth.se \\ * Correspondence: anders.jarfors@ju.se
}

Received: 2 October 2020; Accepted: 19 November 2020; Published: 23 November 2020

\begin{abstract}
Semisolid casting can provide excellent castings, but the nature of the pore-forming mechanisms has not been properly clarified. In the current communication, it was suggested that hydrogen precipitated during slurry making might have a decisive role in the formation of both gas and shrinkage porosity. Intensive stirring at the end of the slurry making process may act as a degassing step. Without the intense shearing, structures of primary slurry particles form around the hydrogen pores, strongly affecting pore formation and feeding during the intensification stage.
\end{abstract}

Keywords: semisolid casting; porosity; hydrogen; shrinkage; feeding; stirring; degassing

\section{Introduction}

Weight reduction in important industry sectors, such as transports, is essential for meeting the $\mathrm{CO}_{2}$-emission targets [1]. Casting and semisolid processing have been identified as critical processes for design flexibility [2] and to achieve weight reduction [3]. To achieve a sound component from a good quality casting, the slurry properties are essential [4]. The flow behaviour of a metal slurry involves a solid-fraction-dependent viscosity, shear-thinning and a solid-fraction-dependent yield point [5]. In conventional high-pressure die-casting (HPDC), it has been shown that hydrogen is not an issue as gas entrainment through advection is dominant [6]. The higher effective viscosity in the slurry will reduce turbulence and significantly reduce porosity [4]. This may make the hydrogen content important to control in semisolid casting for porosity management.

The solubility of hydrogen in the solid phase is significantly lower than in the liquid phase [7], and it is also difficult to nucleate gas bubbles [8]. It is thus necessary to have a suitable substrate for heterogeneous nucleation to create a pore, and in a semisolid slurry, the number of substrates in the form solid/liquid phase interfaces is abundant.

Once pores are formed the mechanics of a solid, as well as a slurry with a yield point, will change and add an element of compressibility to it, meaning that the von Mises cylinder becomes an ellipsoid allowing for hydrostatic pressure to cause deformation [9]. These pores may also be filled. There is a complex interaction between the solid phase arrangement and the melt to allow a pore to be filled, by the melt. This opens for an even more complex interaction between a solid, liquid and gas in a manufacturing process involving a semisolid state.

The current communication aims to show some empirical observations that shed light on these complex interactions. 


\section{Materials and Methods}

The materials used was Magsimal 59 (AlMg5Si2Mn), an alloy well suited for use in semisolid casting. The material was molten using a resistance furnace with a $200 \mathrm{~kg}$ capacity, and no degassing action was taken, suggesting that the melt was saturated with hydrogen. The slurry was fabricated using the RheoMetal Process, where the melt is ladled from the furnace and the Enthalpy Exchange Material (EEM) is cast around a steel rod, Step 1 and 2, Figure 1a. The slurry is then produced by stirring the solid EEM into the ladle and then pouring the slurry into the shot chamber (Step 3 and 4 , Figure 1a. In the current study, a standard set-up, left in Figure 1 band a non-standard set-up, right in Figure $1 \mathrm{~b}$ were used. For the non-standard set-up, the rod har SiC coated wings, allowing for additional shearing of the slurry without breaking the surface a second time. Processing temperatures (Melt temperature of $700^{\circ} \mathrm{C}$ and start of stirring at $630^{\circ} \mathrm{C}$ ) and timings were kept constant (20 s with 900 $\mathrm{rpm}$ ) and identical for both processing routes, only to see the influence of the stirring. Stirring rotation rate was chosen to avoid the formation of a top surface vortex, entraining gas into the melt/slurry. The material was cast using a 50 ton Vertical HPDC machine. In the current study, 10 samples were produced with 4 samples for intense stirring and 6 samples with standard processing.

Optical microscopy (Olympus Microscope) was used to observe the nature of the porosity.

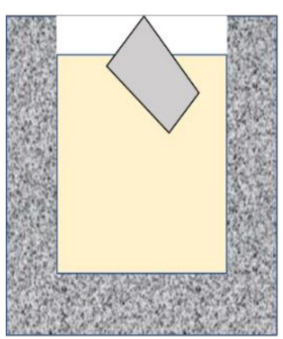

(1)

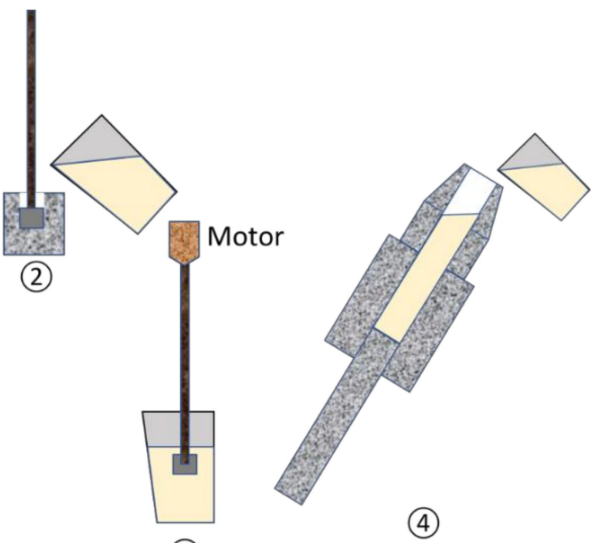

(3)

(4) (a)

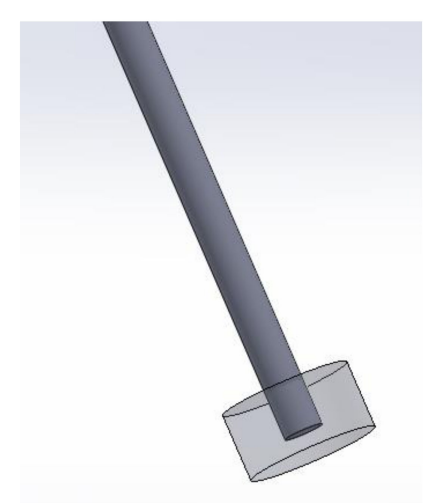

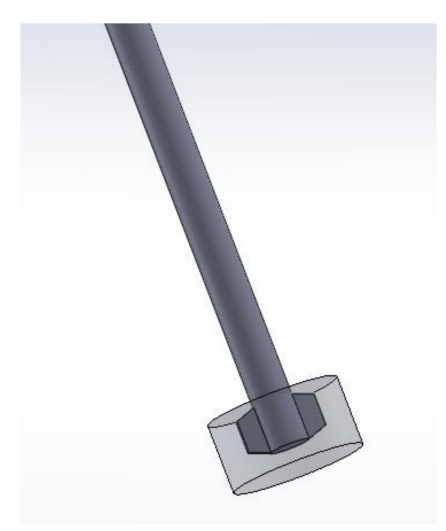

(b)

Figure 1. Schematic illustration of the slurry fabrication process with; (a) The RheoMetal ${ }^{\mathrm{TM}}$ process steps as (1) Ladling, (2) Casting the Enthalpy Exchange Material (EEM), (3) Stirring in the solid EEM to make the slurry, (4) Pouring the slurry into the shot chamber, and (b) Standard RheoMetal ${ }^{\mathrm{TM}}$ processing rod and EEM (Left) and Intense shearing set-up with wings added to the rod cast into the EEM body (right). 


\section{Results and Discussion}

The observed microstructures for the two processing conditions are shown in Figure 2. The intense shearing has resulted in a near pore-free microstructure (Figure 2a). The white phase is primary precipitated $\alpha_{1}-\mathrm{Al}$ particles produced in the RheoMetal process, and the grey regions are a mixture of finer $\alpha_{2}-\mathrm{Al}$ particles/dendrites and the eutectic with $\mathrm{Al}$, and $\mathrm{Mg}_{2} \mathrm{Si}$. Figure $2 \mathrm{~b}$ shows the same material processed using the conventional methodology with a higher gross porosity formed in the centre. Here, it should be noted that there exists in both cases, a nearly $\alpha_{1}$-Al particle-free outer layer as the slurry particle migrates inwards during filling $[10,11]$. It should also be noted that a strong shear band has formed under conventional processing (Figure 2b), and a tendency for the same is seen in Figure 2a [12]. These processes cause an agglomeration of the $\alpha_{1}$-Al particles in the central regions, which then will give rise to a slurry with a higher yield point of the slurry, provided that the microstructural morphology would allow for the required strength build-up to occur. The results in that the inner part would flow more like a plug, preserving structures from the slurry fabrication, with shear concentrated to the surface region with low viscosity.
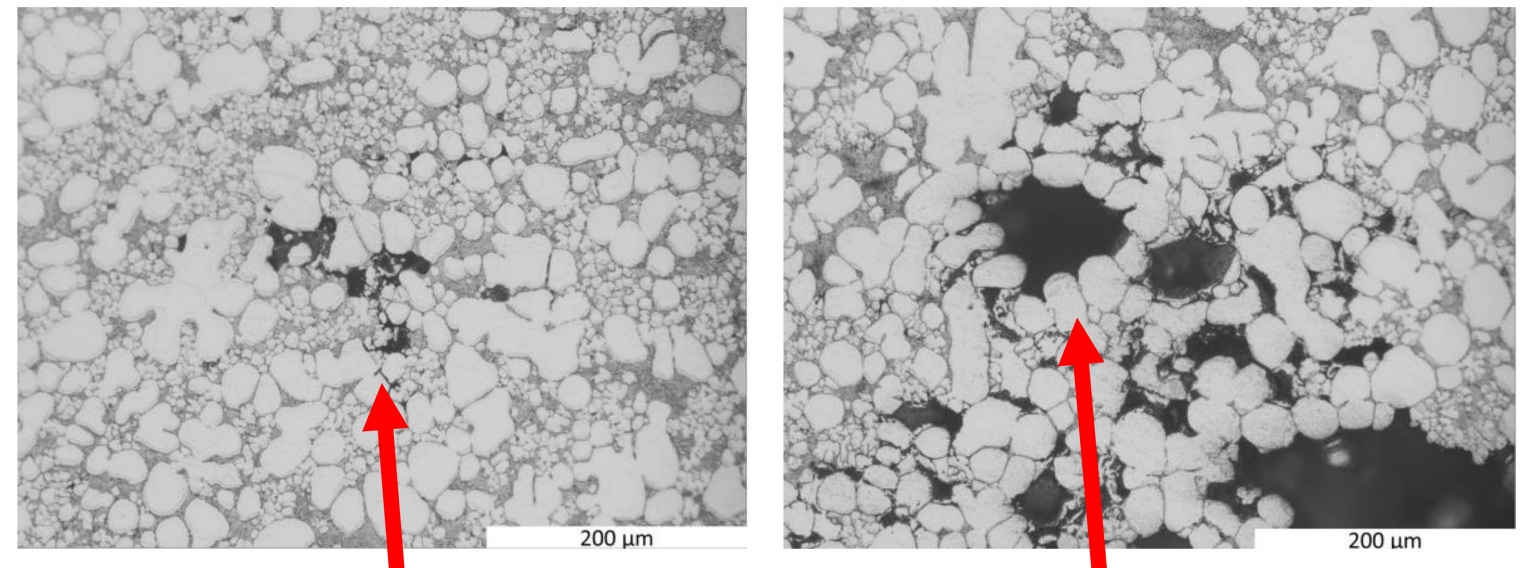

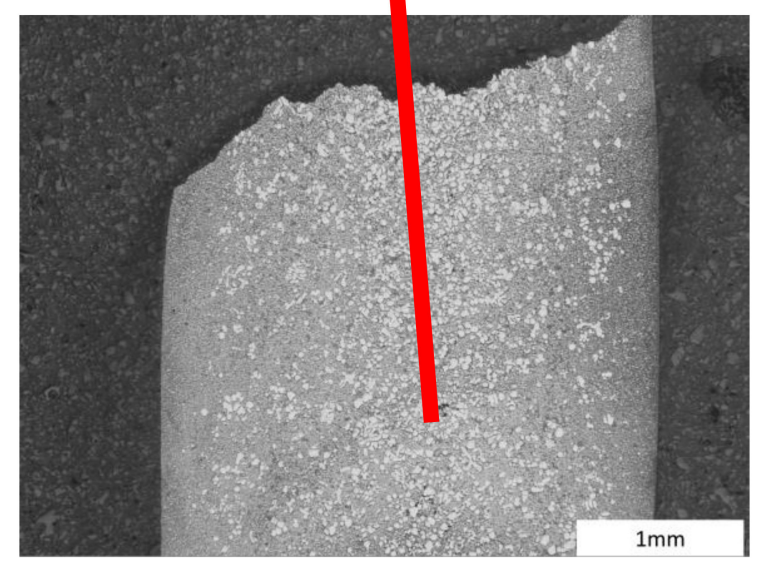

(a)

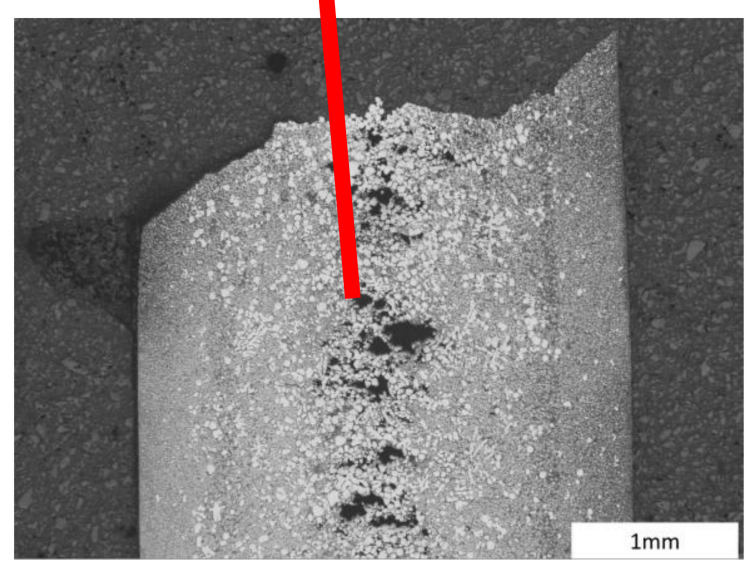

(b)

Figure 2. Illustration of the overall microstructures, in a longitudinal cross-section along the central axial plane of the tensile sample after tensile testing, obtained for the cast Magsimal 59 alloy and the specific feature of interest using: (a) Intensified shearing; and (b) Standard RheoMetal ${ }^{\mathrm{TM}}$ processing.

Gas entrainment would result in a random distribution of small rounded pores. In the current casting, the pore distribution is located in the centre where the fraction of primary $\alpha_{1}$-Al particles is high (Figure 2a,b). This strongly suggests that the porosity is dominated by shrinkage porosity. It should be noted that many of the pores are well-rounded, which suggests that gas has been involved 
in the pore formation. In a $3 \mathrm{~mm}$ thick casting, no strong temperature gradient is formed, and a conventional centerline defect is not formed.

The suggested porosity formation mechanism is illustrated in Figure 3a. As the slurry is made and the temperature is lowered in the melt, solid $\alpha_{1}$-Al particles precipitates and reject hydrogen to the melt. At some point, a hydrogen bubble may form at a solid/liquid interphase surrounding a particle since heterogeneous nucleation is a necessity [8]. When formed, such a bubble will interact with other adjacent solid particles, both during the slurry making and during the mould filling. The bubble will due to its compressible nature allow the surrounding solid phase to move towards the pore and form a shell-like structure seen in Figure 2a, here seen as the ring-shaped feature, also illustrated in Figure 3a.

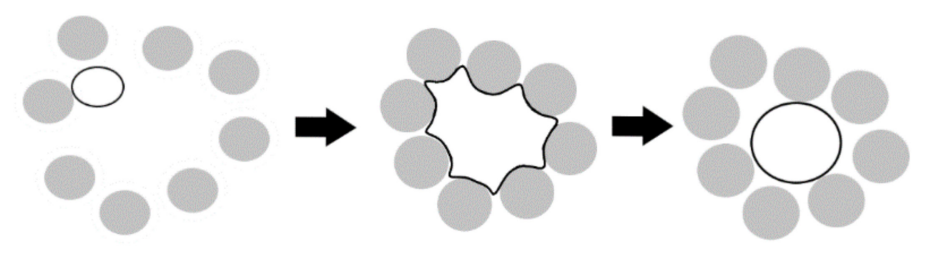

(a)

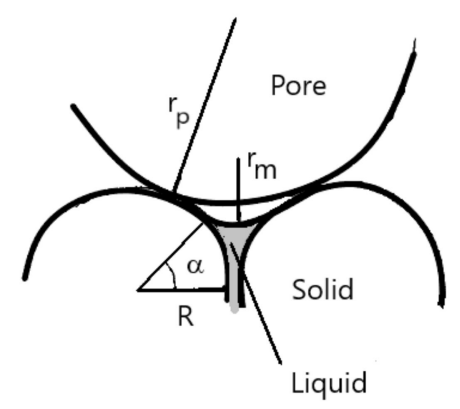

(b)

Figure 3. Illustration of the pore formation and profiling mechanisms: (a) Pore formation sequence with nucleation, precipitation and compression as well as the final stage of partial filling, and (b) Geometries illustrating conditions for pore filling, freely after [13].

The events during slurry making are illustrated by the difference in porosity between the sample using extensive shearing (Figure 2a) and the standard stirring treatment (Figure 2b). The hydrogen gas, precipitating at the solid/liquid interphases, has difficulties in escaping due to a higher fraction of $\alpha_{1}$-Al particles. However, intense shearing will break the structures in the slurry, making it more malleable, with reduced viscosity, and also making it possible for the gas bubbles to escape through buoyancy-driven effects. In the case of the conventional stirring, this action is significantly less effective, resulting in high porosity in the $\alpha_{1}$-Al particles rich regions, where all the pores are agglomerating.

Post slurry making, a gas bubble would, as mentioned, change the mechanical behaviour, adding yielding and deformation due to hydrostatic pressure to the cause of deformation. The combination of cooling with continued gas precipitation and solid-phase precipitation and increasing pressure, especially during the final intensification stage of the casting process, will move the particles towards each other as the bubble is growing to the second stage in Figure $3 a$, which also is seen in the highlighted region in Figure 2b. The irregular shape is partially depending on the wetting and surface tension together with the fact that melt is being transported to the areas with the largest volume of shrinkage, 
i.e., regions with little or few $\alpha_{1}$-Al particles, far away from the centre of the casting, closer to the outer surface. For the pore to fill with melt, there is a requirement that the melt meniscus radius $r_{m}$, Figure $3 \mathrm{~b}$ becomes identical to the pore radius, $r_{p}$ [13]. The filling depends on particle size, $R$, slurry temperature, wetting angle $\alpha$ and in the final intensification stage, the applied pressure, supporting pore filling.

Pores in the order of $0.1 \mathrm{~mm}$ appear intact, while larger pores have collapsed in Figure $2 \mathrm{~b}$. The collapsed pores appear to have been compressed along the centerline suggesting an axial pressure which then would be in the direction from the plunger towards the venting which would suggest that the intensification pressure drove this. The collapsed structures are seen as partial rings, arcs, of $\alpha_{1}-\mathrm{Al}$ particles in Figure $2 b$.

It should here be noted that, as the gas porosity was removed by the intense shearing, no such extensive ring-shaped structures, nor collapsed and deformed features, could be found in the microstructures, as shown in Figure 2a. The fact that the intense shearing removed hydrogen is also distinctly seen as the overall difference in porosity.

\section{Conclusions}

The origin of porosity in semisolid casting was discussed in this communication. The main conclusions were:

1. It appears as if intense shearing can act as a degassing step in semisolid casting.

2. Structures were formed in the proximity of primary precipitated slurry particles suggesting that gas pores, presumably hydrogen bubbles, form near or at the solid-liquid interfaces.

3. These particle structures will, together with the gas pores, drive the formation of a combined gas and shrinkage porosity. Smaller structures will prevail, and larger structures will collapse during intensification as the existing porosity will allow the material to yield under compressive stress.

Author Contributions: Conceptualization of the paper, A.E.W.J.; methodology, Q.Z.; investigation, Q.Z.; writing-original draft preparation, A.E.W.J.; writing-review and editing, A.E.W.J., S.J. and Q.Z.; visualization, A.E.W.J.; supervision, A.E.W.J., and S.J.; project administration, A.E.W.J.; funding acquisition, A.E.W.J. All authors have read and agreed to the published version of the manuscript.

Funding: This research was funded by VINNOVA, under the project ReCKA, grant number 2018-02831.

Acknowledgments: The authors are indebted to the industrial support for the project given by Scania CV, Volvo Car Corporation and Comptech AB. Arne Dahle is also acknowledged for valuable comments and discussions on hydrogen and degassing related to two-phase materials.

Conflicts of Interest: The authors declare no conflict of interest. The funding agency had no part in the research formulation of the project, and there was no influence from the industrial partners in the collection, analyses or interpretation of data; in the writing of the manuscript, or in the decision to publish the results.

\section{References}

1. Serrenho, A.C.; Norman, J.B.; Allwood, J.M. The impact of reducing car weight on global emissions: The future fleet in Great Britain. Philos. Trans. R. Soc. A Math. Phys. Eng. Sci. 2017, 375, 20160364. [CrossRef] [PubMed]

2. Jarfors, A.E.W.; Seifeddine, S. Metal Casting. In Handbook of Manufacturing Engineering and Technology; Springer: Berlin, Germany, 2015; ISBN1 9781447146704. ISBN2 9781447146698.

3. Jarfors, A.E.W.; Zheng, J.C.; Chen, L.; Yang, J. Recent advances in commercial application of the rheometal process in China and Europe. Solid State Phenom. 2019, 285, 405-410. [CrossRef]

4. Fan, Z. Semisolid metal processing. Int. Mater. Rev. 2002, 47, 49-85. [CrossRef]

5. Modigell, M.; Pola, A.; Tocci, M. Rheological characterization of semisolid metals: A review. Metals 2018, 8, 245. [CrossRef]

6. Seifeddine, S.; Poletaeva, D.; Ghorbani, M.; Jarfors, A. Heat Treating of High Pressure Die Cast Components: Challenges and Possibilities. In Light Metals; Grandfield, J., Ed.; Springer: Berlin, Germany, 2014; pp. 183-188. [CrossRef] 
7. Tiryakioğlu, M. Solubility of hydrogen in liquid aluminium: Reanalysis of available data. Int. J. Cast Met. Res. 2019, 32, 315-318. [CrossRef]

8. Tiryakioğlu, M. On the heterogeneous nucleation pressure for hydrogen pores in liquid aluminium. Int. J. Cast Met. Res. 2020, 33, 153-156. [CrossRef]

9. Doraivelu, S.; Gegel, H.; Gunasekera, J.; Malas, J.; Morgan, J.; Thomas, J., Jr. A new yield function for compressible PM materials. Int. J. Mech. Sci. 1984, 26, 527-535. [CrossRef]

10. Laukli, H.I.; Gourlay, C.M.; Dahle, A.K. Migration of crystals during the filling of semisolid castings. Metall. Mater. Trans. A Phys. Metall. Mater. Sci. 2005, 36, 805-818. [CrossRef]

11. Law, M.; Hulme-Smith, C.N.; Matsushita, T.; Jönsson, P.G. Assessment of mechanisms for particle migration in semisolid high pressure die cast aluminium-silicon alloys. J. Manuf. Mater. Process. 2020, 4, 51. [CrossRef]

12. Gourlay, C.M.M.; Laukli, H.I.I.; Dahle, A.K.K. Defect band characteristics in Mg-Al and Al-Si high-pressure die castings. Metall. Mater. Trans. 2007, 38, 1833-1844. [CrossRef]

13. Lu, P.; Xu, X.; Yi, W.; German, R.M. Porosity effect on densification and shape distortion in liquid phase sintering. Mater. Sci. Eng. A 2001, 318, 111-121. [CrossRef]

Publisher's Note: MDPI stays neutral with regard to jurisdictional claims in published maps and institutional affiliations.

(C) 2020 by the authors. Licensee MDPI, Basel, Switzerland. This article is an open access article distributed under the terms and conditions of the Creative Commons Attribution (CC BY) license (http://creativecommons.org/licenses/by/4.0/). 